\title{
Health Inequalities through the Lens of Health Capital Theory: Issues, Solutions, and Future Directions
}

\author{
Titus J. Galama ${ }^{a, b}$ and Hans van Kippersluis ${ }^{c, d}$ \\ aUniversity of Southern California, Dornsife College Center for Economic and Social Research, \\ Los Angeles, USA bRAND Corporation, Santa Monica, USA 'Erasmus School of Economics, \\ Erasmus University Rotterdam, The Netherlands ${ }^{d}$ Tinbergen Institute, The Netherlands
}

\begin{abstract}
We explore what health-capital theory has to offer in terms of informing and directing research into health inequality. We argue that economic theory can help in identifying mechanisms through which specific socioeconomic indicators and health interact. Our reading of the literature, and our own work, leads us to conclude that non-degenerate versions of the Grossman model (1972a;b) and its extensions can explain many salient stylized facts on health inequalities. Yet, further development is required in at least two directions. First, a childhood phase needs to be incorporated, in recognition of the importance of childhood endowments and investments in the determination of later-life socioeconomic and health outcomes. Second, a unified theory of joint investment in skill (or human) capital and in health capital could provide a basis for a theory of the relationship between education and health.
\end{abstract}

\section{Introduction}

Health is a basic necessity of life. Inequalities in health constitute inequalities in people's capability to function. The right to the highest attainable level of health is enshrined in the charter of the World Health Organization (WHO) and in many international treaties (e.g., article 25 of the Universal Declaration of Human Rights). Yet, the majority of people in the world do not enjoy the health that is biologically possible (WHO, 2008); the socially and economically disadvantaged generally experience worse health outcomes (e.g. Mackenbach et al. 1997).

Health inequality is not only an infringement of equity: the avoidable mortality and morbidity of lower socioeconomic groups also impedes productivity and threatens to undermine economic growth and prosperity (WHO, 2001). It is no surprise then that a primary goal of many governments' health policies is the reduction of health inequities (e.g., US Healthy People 2020 initiative, 2010).

A significant body of research across multiple disciplines has been devoted to documenting and explaining the substantial disparities in health between socioeconomic groups. The recent literature has concentrated on estimating causal effects. It has been established that causality runs in both directions: evidence is strong that health affects socioeconomic characteristics such as employment and income (e.g. Smith, 1999; Garcia-Gomez, van Kippersluis, O'Donnell, and van Doorslaer, 2013), and the evidence base is growing that socioeconomic characteristics, in particular education, affect health (e.g. Lleras-Muney, 
2005; Conti, Heckman and Urzua, 2010; Van Kippersluis, O'Donnell, and van Doorslaer, 2011). ${ }^{1}$

A major limitation of the existing literature is the failure to uncover the mechanisms underlying the causal relationships: for example, it is not known how the educated achieve their health advantage (Cutler and Lleras-Muney, 2010). Case and Deaton (2005) note that "it is extremely difficult to untangle the links between work, earnings, health, and education, without some sort of guiding framework". In this chapter we explore what economic theory, and in particular health-capital theory developed in the seminal work of Michael Grossman (1972a;b), can offer in terms of improving understanding of the causes of health inequalities.

We will argue that economic theory can help in identifying mechanisms through which specific socioeconomic indicators, such as education, income and wealth, and health interact. Identifying the mechanisms is vital to evaluation of the normative case for reducing health inequalities and the design of policies that are effective in doing so (Deaton, 2002).

Based on our reading of the literature, and our own work, we conclude that the Grossman model (1972a;b) provides a solid foundation for the study of health inequalities across socioeconomic groups. With the extensions proposed by Ehrlich and Chuma (1990), Case and Deaton (2005), and Galama and Van Kippersluis (2010), health-capital theory can explain important stylized facts on health inequalities. Yet, further development is required in at least two directions. First, theories of health inequalities need to include a childhood phase, recognizing the importance of childhood endowments and investments in the determination of later-life socioeconomic and health outcomes (e.g., Heckman, 2006; Cunha and Heckman, 2007). Second, the human- and health-capital literatures have developed separately and currently no unifying theory exists. As a result, both theories fall short of explaining the strong association between education and health. We outline our initial thoughts on both of these areas for future research. We believe advancements in these directions are feasible and anticipate them to occur in the next few years.

This chapter is organized as follows. In the next section we discuss some salient empirical stylized facts on health inequality that economic theory should be able to capture. The third section focuses on health-capital theory: it starts from the conventional Grossman model, presents issues with the model, proposes solutions, and discusses possible future directions of theory development. Finally, we summarize our findings and conclude.

\section{Stylized Facts on Health Inequality}

In this section we discuss six of the most important stylized facts that emerge from the rich empirical literature on socioeconomic inequalities in health. This list is not meant to be exhaustive, or even comprehensive. It reflects our personal view of stylized facts that ought to be captured by an economic theory aiming to provide insight into health inequalities. Further, we stress that the focus is on socioeconomic inequalities only, and we do not discuss racial or gender disparities in health (see e.g., Arber and Cooper, 1999; Annandale and Hunt, 2000; Levine et al. 2001; Williams and Jackson, 2005 for discussions of those). Also, we restrict attention to the developed world; see Cutler and Lleras-Muney (2012) for a review including developing countries.

Our six stylized facts on health inequality are:

\footnotetext{
${ }^{1}$ Yet, see Albouy and Lequien (2008) and Clark and Royer (2013) for studies that failed to identify an effect of education on mortality.
} 
1) Health is strongly associated with socioeconomic status, irrespective of the measures used, and irrespective of the institutional setting.

Disparities in health across socioeconomic status (SES) groups are substantial. For example, Case and Deaton (2005) show how in the United States, a 20-year-old low-income (bottom quartile of family income) male, on average, reports to be in similar health as a 60-year-old high-income (top quartile) male. Inequalities in health exist across all measures of SES, such as education, income, and wealth, and across all indicators of health, including subjective measures of health, and more objective measures such as the onset of chronic diseases, disability and mortality (e.g., Adler et al. 1994; Marmot, 1999; Smith, 1999). Disparities are found in countries with relatively low levels of protection from loss of work and health risks, such as the U.S., and those with stronger welfare systems, such as the Netherlands (House et al. 1994; Smith 1999; 2007; Case and Deaton, 2005; van Kippersluis, O'Donnell, van Doorslaer and van Ourti, 2010).

2) Health inequalities between low- and high-SES groups increase over the life cycle until age 60, after which they narrow.

In cross-sectional data, health differences across low- and high-SES groups exist already by age 20 , and increase gradually until around age 60 , after which the health differences appear to narrow. Figure 1 illustrates how these relations are remarkably similar between countries (U.S. and Netherlands shown).

Interpretations of the observed widening and subsequent narrowing of the SES-health gradient with age differ in the extent to which the observed pattern is presumed to reflect substantive changes in the relationship between SES and health over the life course, as opposed to simply being the product of methodological limitations. According to the cumulative-advantage hypothesis, the SES-health gradient increases over the life course due to gestation of the effects. For example, the health effects of socioeconomic differences in smoking become apparent only in middle age (Ross and Wu, 1996; Lynch, 2003). Selective mortality and cohort effects obscure this process, as lower SES people are more likely to die, resulting in an apparently healthier surviving disadvantaged population, and explaining the narrowing of disparities in old age. The competing view, the age-as-leveller hypothesis, proposes that biological determinants increase in importance relative to socioeconomic determinants at older ages (Herd, 2006), leading to smaller socioeconomic inequalities at later ages. Generally, the evidence is consistent with a cumulative-advantage process operating until middle age, with age indeed acting as a leveller in old age (House et al. 1994; Deaton and Paxson, 1998; Beckett, 2000; Case and Deaton, 2005; Smith 2007).

3) Health insurance and access to health care only explain a small fraction of health inequalities - occupation, health behaviours, and the ability to process information seem more important.

It has been argued that utilization of medical services and access to care explains only part of the observed inequalities in health by SES (Adler, Boyce, Chesney, Folkman, and Syme, 1993). Physical and psychosocial hazards at work seem to play a larger role: low SES individuals more often perform physically demanding manual labour or are employed in jobs associated with greater psychosocial stressors than high SES individuals, and their health deteriorates faster as a consequence (Marmot, Ryff, Bumpass, Shipley, and Marks, 1997; Borg and Kristensen, 2000; Case and Deaton, 2005; see also Ravesteijn, van Kippersluis and van Doorslaer in this volume).

Additionally, inequalities arise due to differences in health behaviours: higher SES people are less likely to smoke, drink heavily, or be obese (Cutler, Lleras-Muney and Vogl, 2011). Fuchs (1986) even argues that in developed countries, it is personal lifestyles that cause the 
greatest variation in health. How SES affects health behaviours is largely unclear, yet the ability to process new information and to take advantage of new medical technologies seems important (Goldman and Smith, 2002; Lleras-Muney and Lichtenberg, 2005; Glied and Lleras-Muney, 2008). This suggests that access to health care and technology does have an indirect role in generating health inequalities.

4) There exists an important "reverse causality" effect of ill-health on labour force participation, income and wealth

One of the dominant pathways responsible for the association between health and economic circumstances is the strong effect health has on labour force participation, earnings and wealth, especially in middle age. Unhealthy individuals drop out of the labour force sooner, and lose income as a result. This explanation was proposed by Smith $(1999 ; 2007)$, and Case and Deaton (2005), and has been corroborated by quasi-experimental evidence of the effect of sudden health shocks on earnings and income (Møller Dano, 2005; Garcia-Gomez et al. 2013; and Halla and Zweimuller, 2013).

5) Among dimensions of socioeconomic status, education seems to be the most important determinant of health

Cutler et al. (2011) argue that the evidence points to no or only very limited impact of income or wealth on health (see also Smith, 1999; Adams et al. 2003; Michaud and Van Soest, 2008). Yet, this view is not unequivocally accepted. For example, Lynch, Kaplan and Shema (1997) suggest that accumulated exposure to economic hardship causes bad health.

Far less controversy exists on education being a powerful determinant of health. There is accumulating evidence that education has a causal effect on health (e.g. Lleras-Muney, 2005; Oreopoulos, 2006; Conti et al. 2010; Van Kippersluis et al. 2011), although not all studies find this (Albouy and Lequien, 2008; Clark and Royer, 2013).

6) A large part of the health gradient may be due to early childhood endowments and investments

In a series of papers, David Barker and co-authors demonstrated the importance of foetal growth on later-life health outcomes (e.g., Barker, 1995; see also Almond and Currie, 2011a). More recently, James Heckman and colleagues have emphasized the role of childhood cognitive and non-cognitive abilities in determining both education and health outcomes in later life (e.g., Cunha and Heckman, 2007; Conti et al. 2010; see also Almond and Currie, 2011b).

This evidence, combined with strong evidence that parental, especially maternal, SES influences the evolution of child health (Case et al. 2002; Currie and Stabile 2003; Currie, 2009), suggests that a large part of the SES-health gradient may be determined very early in life. As Cutler et al (2011, p. 154) note, this suggests also an intergenerational aspect of inequalities: "poor childhood health begets limited means in adulthood, which in turn begets poor childhood health for the next generation."

\section{Health Capital Theory}

A natural framework of analysis is provided by human-capital theory, the foundations of which have been laid by the seminal works of Schultz (1961), Becker (1964), Ben-Porath (1967), and Mincer (1974). While this theory has proven very effective in contributing to the understanding of decisions with respect to education and (on-the-job) training, it falls short in this regard with respect to health. For example, Becker (1964) observes that investments in human capital should fall with age as the period over which returns can be accrued decreases. Yet, investments in health clearly increase with age, even after retirement when 
health has lost its importance in generating earnings. This, and other distinctions identified by, e.g., Mushkin (1962) between health and other types of human capital led to the development of the so-called health-capital model by Grossman (1972a,b; 2000). The health-capital model has served as the workhorse model in health economics, and has greatly contributed to the understanding of a wide range of phenomena in health and health care.

\section{Model formulation}

In the health-capital model, health is treated as a stock that provides direct utility

$$
\int_{0}^{T} U[C(t), H(t)] e^{-\beta t} d t
$$

where utility $U[\cdot]$ is provided by consumption $C(t)$ and health $H(t)$ and $\beta$ is the rate at which individuals discount future utility. Health depreciates with age at the biological aging rate $d(t)$

$$
\frac{\partial H(t)}{\partial t}=f[I(t)-d(t) H(t)
$$

The aging process $d(t)$ can be countered through health investments $I(t)$, which improve health through the production process $f[I(t)]$ and consists of direct outlays $m(t)$ (e.g., medical expenses) and own time inputs $\tau_{I}(t)$ (e.g., exercise). Assets $A(t)$ increase with the rate of return to capital $r$

$$
\frac{\partial A(t)}{\partial t}=r A(t)+Y[H(t)]-p_{C}(t) X_{C}(t)-p_{m}(t) m(t)
$$

with earnings from labour $Y[H(t)]$ (a function of health), and decrease with expenditures on consumption goods and services $X_{c}(t)$ and on health investment goods and services $m(t)$ at prices $p_{c}(t)$ and $p_{m}(t)$, respectively. Earnings consist of the time spent working in a period $\tau_{w}(t)$ multiplied by the wage rate $W(t): Y[H(t)]=W(t) \tau_{w}(t)$. The total time available in a period $\Omega$ is the sum of all its possible uses

$$
\Omega=\tau_{w}(t)+\tau_{I}(t)+\tau_{C}(t)+S[H(t)]
$$

$\tau_{w}(t)$ (work), $\tau_{I}(t)$ (health investment), $\tau_{c}(t)$ (own-time inputs into consumption) and $s[H(t)]$ (sick time). Last, we have initial and end conditions: $A(0), A(T), H(0), H(T)$, and individuals die when health reaches a minimum level $H(T)=H_{\text {min }}$.

A few key concepts of the model are that:

1. Individuals demand good health (i) for its production benefit: health increases earnings (reduced sick time, enhanced productivity ${ }^{2}$ ), and (ii) for its consumption benefit: health provides utility. This is in contrast to other components of human capital, which are generally not modelled as providing a consumption (utility) benefit.

\footnotetext{
${ }^{2}$ In case the wage rate is also a function of health
} 
2. The demand for health investment is a derived demand: individuals invest in health due to the underlying demand for good health, e.g., not because they enjoy consuming care.

3. The efficiency of the health investment process $I(t)=I\left[m(t), \tau_{I}(t) ; E\right]$ increases with knowledge $E$ as the more educated are assumed to be more efficient consumers and producers of health care.

\section{Issues}

Is the Grossman model and its extensions able to explain our six stylized facts on health differences across SES groups? It does an adequate job in capturing stylized fact 1 . The model predicts a positive association between health and socioeconomic indicators such as education and wealth. However, Case and Deaton (2005) have argued that health-capital models are unable to explain differences in the rate of health decline (not just the level) between SES groups, i.e. it fails to describe stylized fact 2 . They note that “... If the rate of biological deterioration is constant, which is perhaps implausible but hardly impossible, ... people will "choose" an infinite life ...". Hence, a feature of the model is that complete health repair is possible, if the rate of biological aging $d(t)$ is constant. Declines in health status are driven not by the rate of biological aging $d(t)$, but by its rate of increase $\partial d(t) / \partial t$. Only if SES differences exist in this rate of increase can the widening of the gradient until old age be explained.

An important stylized fact of the demand for medical care is that it is the unhealthy, not the healthy, that use medical services most intensively, and this is true regardless of whether bad health was the result of a sudden health shock or the result of more gradual health deterioration. However, as Wagstaff (1986) and Zweifel and Breyer (1997) have pointed out, health-capital models are unable to predict this observed negative relation between health and the demand for medical care. Introspection and casual observation further suggests that healthy individuals are those that began life healthy and that have invested in health over the life course. Yet, Usher (1976) has pointed to the lack of "memory" in the model. The solution for health does not depend on its initial value or the histories of health investment and biological aging (see, e.g., equations 42, 45 and 47 in Grossman, 2000). Thus the model would, for example, not be able to reproduce the observation that health and investments in early childhood have sustained effects on adult outcomes (Almond and Currie, 2011b). The static nature of the derived solution for health is also incompatible with the inherently dynamic nature of the model formulation (see equation (2) above).

In our own work (Galama and Van Kippersluis, 2010; Galama, 2011) we have come to the conclusion that there is a fairly simple, but so far largely misunderstood, solution to these limitations of the Grossman model, as follows. The health-capital literature makes two important assumptions, for mathematical convenience, which lead to a degeneracy of the solution to the optimization problem. To recall the definition, in mathematics, a degenerate case is a limiting case in which a class of solutions changes its nature so as to belong to another, usually simpler, class. A degenerate case thus has special features, which depart from the properties that are generic in the wider class, and the nature of the degenerate solution is generally lost under a small perturbation of the degenerate system. This is exactly the case with 11 the Grossman model under the commonly used assumptions of 1) a health production function in the dynamic (transition) equation for health (see (2)) that is linear in health investment, i.e., $f[I(t)]=I(t)$, and 2) a Cobb-Douglas constant returns to scale (CRTS) relation between investment in health $I(t)$ and its inputs of own time $\tau_{I}(t)$ and health investment goods/services purchased in the market $m(t)$, i.e., $I(t)=\mu(t) m(t)^{k} \tau_{I}(\mathrm{t})^{1-k}$. 
Under these two assumptions the Hamiltonian of the constrained optimization problem is linear in $I(t), \tau_{I}(t)$, and $m(t)$. Since the optimality condition for these three (related) controls are derived by taking the derivative of the Hamiltonian with respect to the controls, the controls themselves are no longer part of the optimality condition (they drop out because of the imposed linearity) and their value cannot be determined (see Galama, 2011, for more detail). ${ }^{3}$ Ehrlich and Chuma (1990) were the first to note this indeterminacy ("bang-bang") problem. Still, the importance of this observation appears to have gone largely unnoticed: contributions to the literature that followed the publication of Ehrlich and Chuma's work in 1990 have continued to make the two standard assumptions ${ }^{4}$ and the issue is not touched upon in a very recent debate on the model (Zweifel, 2012; Kaestner, 2013).

In Galama (2011) we develop the Grossman model with a health-production process with decreasing returns to scale (DRTS) in health investment (addressing the degeneracy, as in Ehrlich and Chuma, 1990) and show that it addresses major criticisms levelled at the model.

${ }^{5}$ Under plausible assumptions, the theory now shows that the health of wealthy and educated individuals declines more slowly, initially widening the gradient, and that the gradient subsequently narrows as a result of mortality selection and increased health investment by lower SES individuals due to rapidly declining health. In short, with these changes the health-capital model can account for stylized fact 2. Further, current health status is found to be a function of the initial level of health and the histories of prior health investments (addressing concerns raised by Usher, 1976); health investment rapidly increases near the end of life; and length of life is finite as a result of limited life-time resources (addressing concerns raised by Case and Deaton, 2005).

Thus, the Grossman model, in our opinion, provides a solid foundation for a theory of health inequalities. The criticisms of the model have largely overlooked the fact that the literature has focussed on a highly unusual degenerate case and that reformulations of the theory can address its major limitations. ${ }^{6}$

\section{Toward a theory of health inequality}

In Galama and Van Kippersluis (2010) we developed a theory of disparities in health between SES groups, based on the Grossman model with six additional features in order to capture the stylized facts described above.

First, we assume decreasing returns to scale in health investment of the health production function, which addresses the degeneracy of linear investment models (Ehrlich and Chuma, 1990; Galama, 2011) and, in addition to predicting the observed association between measures of health and SES (stylized fact 1), captures the widening and subsequent narrowing of health inequalities with age (stylized fact 2).

\footnotetext{
${ }^{3} \mathrm{~A}$ small perturbation from linearity in health investment results in drastically different model solutions. Even if we were to believe that the health production process was linear (and few, we believe, will make this argument) it surely won't be so with very exact precision.

${ }^{4}$ E.g., Bolin et al. (2001; 2002); Case and Deaton (2005); Erbsland, Ried and Ulrich (1995); Jacobson (2000); Ried (1998).

5 We further argue for a different interpretation of the health stock equilibrium condition, one of the most central relations in the health capital literature. It is not the relation that determines the equilibrium level of health as it is commonly interpreted (as, e.g., in Grossman 1972a,b; Ehrlich and Chuma, 1990) but rather the optimality (first-order) condition for the level of health investment. 6 An interesting consequence of the literature's focus on the degenerate case is that empirical tests of the Grossman model are still in their infancy. Thus far tests of the Grossman model have almost exclusively relied on the degenerate model (e.g. Grossman, 1972a; Van de Ven and Van der Gaag, 1982; Wagstaff, 1986; 1993; Leu and Doppmann, 1986; Leu and Gerfin, 1992; Van Doorslaer, 1987; Erbsland et al., 1995; Nocera and Zweifel, 1998; Gerdtham et al., 1999; and Gerdtham and Johannesson, 1999). See Galama, Hullegie, Meijer and Outcault (2012) for a first attempt at estimating a linearized equation derived from the more general (non-degenerate) version of the Grossman model. A more recent literature has solved and estimated dynamic formulations (sometimes loosely) based on health-capital theory using dynamic programming techniques, and taking into account a health investment process that is subject to decreasing returns to scale (e.g., Gilleskie, 1998; 2010; Ehrlich and Yin, 2005; Yogo, 2009; Khwaja, 2010; Scholz and Seshadri, 2012; Fonseca et al. 2013; Hugonnier et al. 2013).
} 
Second, following Case and Deaton (2005) individuals choose among jobs with characteristics $z(t)$ which potentially have health consequences. This might be referred to as 'job-related health stress' and can be interpreted broadly, ranging from physical working conditions (e.g., hard or risky labour) to psychosocial aspects of work (e.g., low social status, lack of control, repetitive work, etc). The decision to engage in unhealthy labour is governed by the relative benefit of a possible wage premium $\partial Y(t) / \partial z(t)>0$ versus the cost in terms of a higher health deterioration rate $\partial d(t) / \partial z(t)>0$ (stylized fact 3$)$.

Third, lifestyles and consumption patterns may affect the biological aging rate (Case and Deaton, 2005; see also Forster, 2001). We distinguish healthy consumption $C_{h}(t)$ (such as the consumption of healthy foods, sports and exercise) from unhealthy consumption $C_{u}(t)$ (such as smoking, excessive alcohol consumption). Healthy consumption provides utility $\partial U$ $(t) / \partial C_{h}(t)>0$, and is associated with health benefits in that it lowers the biological aging rate $\partial d(t) / \partial C_{h}(t)<0$. Unhealthy consumption provides consumption benefits $\partial U(t) / \partial C_{u}(t)$ $>0$ but increases the biological rate of aging $\partial d(t) / \partial C_{u}(t)>0$ (stylized fact 3$)$.

Fourth, we include an endogenous retirement decision that captures possible reverse causality from health to SES (stylized fact 4). Earlier attempts at including a retirement decision in the Grossman model (Galama, Kapteyn, Fonseca, and Michaud, 2013) have had to rely on numerical analyses. But a transversality condition for the optimal retirement age can be obtained from the dynamic envelope theorem (e.g., Caputo, 2005, p. 293).

Fifth, individuals endogenously optimize length of life as in Ehrlich and Chuma (1990). Last, the causal effect of education on income is included in a straightforward manner by assuming a Mincer-type wage relation, in which earnings are increasing in the level of education and the level of experience of workers (e.g., Mincer, 1974).

We perform detailed comparative dynamic analyses to assess the characteristics of the model and generate empirically testable predictions. We find that greater initial wealth, permanently higher earnings (over the life cycle) and a higher level of education induce individuals to invest more in health, shift consumption toward healthy consumption, and enable individuals to afford healthier working environments (associated with lower levels of physical and psychosocial health stresses) and living environments. As a result, they live longer.

The mechanism through which initial wealth, permanent income and education (our measures of SES) operates is by increasing the marginal value of health, thereby increasing the demand for health investment, increasing the health benefit of (and hence demand for) healthy consumption, and increasing the health cost of (and hence reduced demand for) unhealthy working and living environments, and of unhealthy consumption. The more rapidly worsening health of low SES individuals leads to early withdrawal from the labour force, widening the gradient in early- and mid-age, and to shorter lives. Jointly these behavioural choices gradually lead to growing health advantage for higher SES groups with age.

Interestingly, the model predicts a subsequent narrowing of the SES-health gradient, due to mortality selection and because low SES individuals increase their health investment and improve their health-related behaviour faster as a result of their more rapidly worsening health. Thus, consistent with empirical data, the model (in contrast to those extant in the literature) successfully predicts a widening and a subsequent narrowing with age of the gradient in health by SES, and that high-SES individuals have greater longevity and years of good health. 
The theory further suggests that unhealthy consumption is not only a function of the direct monetary cost (e.g., the price of a pack of cigarettes) but also of an indirect health cost (value of health lost), which increases with wealth and with the degree of unhealthiness of the good. As a result, the effect of wealth on unhealthy consumption consists of the usual positive direct effect and an offsetting indirect effect. This leads to the prediction that an unexpected wealth shock increases demand for healthy and moderately unhealthy consumption goods, but decreases demand for severely unhealthy goods. Our theory may thus provide an economic rationale for the observation that wealthy individuals are more likely to drink moderately, but less likely to drink heavily and smoke (Cutler and LlerasMuney, 2010). In an empirical test exploiting both lottery winnings and inheritances as plausibly exogenous variation in wealth, we present evidence that differences in health costs may indeed provide an explanation for behavioural differences, and ultimately health outcomes, between wealth groups (Van Kippersluis and Galama, 2013).

\section{On-going and future directions}

Our theory of health disparities includes lifestyle, health behaviour, job environment, retirement and longevity (in addition to health investment), and is capable of replicating a large number of the stylized facts concerning health inequalities. Two important stylized facts (5 and 6), however, are not yet accommodated.

Regarding stylized fact 6 , an important extension of the theory would be the inclusion of a distinct childhood phase of life. Important socioeconomic differences exist in the evolution of child health (Currie, 2009), and the impact of foetal and early-childhood conditions on health in adulthood are substantial (e.g., Barker, 1995; Almond and Currie, 2011a;b). James Heckman and co-authors discuss the complexity of early childhood skill formation, pointing out that abilities matter, that abilities are multiple in nature, that socio-emotional or noncognitive skills foster the development of cognitive skills, that there are sensitive and critical periods in the development of child abilities, that ability gaps form at early ages and are difficult to remediate at late but not early ages (or stated in a different way -- that the rate of return to investments in disadvantaged children is high compared to interventions targeted to disadvantaged adolescents), and that early investments in children need to be followed up with later investments (e.g., Cunha and Heckman, 2007; Conti et al. 2010). They offer a model of childhood skill formation that exhibits self-productivity, where higher stocks of skills in one period create higher stocks of skills in the next period, and dynamic complementarity, where stocks of skills in one period make investments in the next period more productive (see also Almond and Currie, 2011b).

Extending the theory in this direction would entail adding a distinct childhood period. One might treat the child as passive, in the sense that parents make decisions regarding time investment and financial investment in their children, but the children themselves do not. Parents are motivated by altruism or by an implicit contract with their children to devote time to care for them or support them financially in old age (see, e.g., Ehrlich and Lui, 1991). This would most likely take the form of an overlapping generations model. Each distinct period of life (e.g., childhood, working life, retirement) however can be modelled as consisting of an infinite number of periods (i.e., using continuous time) rather than the commonly employed two or three discrete period models, so that the theory can describe rich lifecycle behaviour and inter-temporal trade-offs between and within generations. Such a childhood phase could be added as an extension to the Grossman-type models discussed in this chapter.

An interesting series of papers by Jacobson (2000) and Bolin et al. $(2001,2002)$ have modelled the production of health by the family (including the health of the child) using the Grossman framework and modelling spouses with common-preferences, as Nash-bargainers, 
and as strategic actors. Their models build on the degenerate linear investment case, however, and it would be of interest to develop them for the general, non-degenerate case.

Regarding stylized fact 5, as Michael Grossman himself observed, ”... we still lack comprehensive theoretical models in which the stocks of health and knowledge are determined simultaneously...The rich empirical literature treating interactions between schooling and health underscores the potential payoffs to this undertaking ..." (Grossman, 2000). Indeed, the human- and health-capital literatures have developed relatively separately, with the human-capital literature either modelling health as a form of human capital that is not very distinct from other forms, or it has treated health as exogenously given. Similarly, health-capital theory has taken knowledge or skill as exogenously given. As a result, both theories fall short of explaining the strong association between education and health.

An important next step in a theory of health inequalities would be the merging of what we term skill- (or human) capital theory with health-capital theory. A basic formulation of a unifying theory would consist of a dynamic model in which skill capital primarily determines the wage rate, while health capital primarily determines the period over which returns accrue (determining the amount of time spent working in a day, retirement and longevity). Investment in skill capital raises the return to investment in health capital, and vice versa, as lifetime earnings are strongly multiplicative in skill and health. Allowing the efficiencies of the skill- and health-capital production processes to be functions of skill capital and health capital may provide several additional reinforcing mechanisms, such as self-productivity and dynamic complementarity (as in Cunha and Heckman, 2007).

\section{Discussion}

Health inequalities across socioeconomic groups raise both ethical and economic concerns, and their reduction is a key priority on the health policy agenda of many nations and regions. Yet, despite numerous policy efforts aimed at reducing disparities over the past decades, if anything, health inequalities seem to have widened rather than narrowed (Meara et al., 2008).

While the scientific evidence on this topic has rapidly expanded, the mechanisms through which health differences across socioeconomic groups emerge and persist are still relatively poorly understood. Economic theory can help guide empirical studies in identifying mechanisms through which specific socioeconomic indicators and health interact.

We identified six stylized facts about health inequalities that we argue a theoretical framework should aim to reproduce. These are: 1) health differences exist across all socioeconomic indicators, irrespective of the institutional setting, 2) socioeconomic health inequality widens until around age 60 , after which it narrows, 3) occupation, health behaviours, and the ability to process information are important mechanisms, 4) there exists an important "reverse causality" effect of ill-health on labour force participation, income and wealth, 5) education seems very important in determining health, and 6) a large part of the health gradient may be due to early childhood endowments and investments.

While the literature has identified several shortcomings of the traditional health-capital model due to Grossman (1972a;b), our claim is that most major limitations can be attributed to the use of a health production process that is linear in health investment. In our work we have found that this widely used but highly unusual degenerate case bears little resemblance to the more general non-degenerate case. 
Introducing a health investment process subject to diminishing returns (which removes the degeneracy), the Grossman model can account for the widening and narrowing of health differences across socioeconomic groups over the lifecycle, for the empirically observed negative association between health and medical care, and addresses several other major issues identified in the literature (Galama, 2011). Thus, we strongly believe that nondegenerate versions of the Grossman model provide a suitable foundation for a theory of health inequalities.

Yet, additional extensions of the traditional Grossman model are required in order to account for stylized facts 3) and 4). In recent work, we made a first attempt towards this aim (Galama and Van Kippersluis, 2010). In the paper, we incorporate six additional features, among which the introduction of decreasing returns to scale in health investment, the introduction of retirement as an endogenous choice, the trade-off between health-detrimental working conditions and a wage premium, and the distinction between healthy and unhealthy consumption goods are the most important. With these additions, the model can account for stylized facts 1) to 4).

The remaining challenges are to reproduce stylized facts 5) and 6). Achieving the first requires further extension to incorporate a childhood phase in which parents invest in the cognitive skills, non-cognitive skills and health of children. Meeting the second challenge will require a theoretical model that explicitly distinguishes between health and other forms of human capital, in order to improve understanding of the role of education in health inequalities.

\section{Acknowledgments}

Research reported in this publication was supported by the National Institute on Aging of the National Institutes of Health under Award Numbers K02AG042452 and R01AG037398. The content is solely the responsibility of the authors and does not necessarily represent the official views of the National Institutes of Health. Titus Galama is grateful to the Erasmus School of Economics of Erasmus University Rotterdam for a Visiting Professorship in the Economics of Human Capital. We thank the editors for helpful comments and suggestions.

\section{References}

Adams P, Hurd MD, McFadden D, Merrill A, Ribeiro T. Healthy, wealthy and wise? Tests for direct causal paths between health and socioeconomic status. Journal of Econometrics. 2003; 112:3-56.

Adler NE, Boyce WT, Chesney MA, Folkman S, Syme LS. Socioeconomic inequalities in health: no easy solution. JAMA. 1993; 269:3140-3145. [PubMed: 8505817]

Adler NE, Boyce T, Chesney MA, Cohen S, Folkman S, Kahn RL, Syme SL. Socioeconomic status and health: The challenge of the gradient. American Psychologist. 1994; 49(1):15-24. [PubMed: 8122813]

Albouy V, Lequien L. Does compulsory education lower mortality. Journal of Health Economics. 2008; 28(1):155-168. [PubMed: 18976824]

Almond, D.; Currie, J. Broken Down by Work and Sex: How our Health Declines. In: Wise, David A., editor. Analyses in the Economics of Aging. Chicago: The University of Chicago Press; 2011. p. 185-212.

Clark D, Royer H. The Effect of Education on Adult Mortality and Health: Evidence from Britain. American Economic Review. 2013 forthcoming.

Conti G, Heckman JJ, Urzua S. The Education-Health Gradient. American Economic Review Papers and Proceedings. 2010; 100:234-238.

Cunha F, Heckman JJ. The technology of skill formation. American Economic Review. 2007; 97(2): $31-47$.

Currie J, Stabile M. Socioeconomic status and child health: why is the relationship stronger for older children? American Economic Review. 2003; 93:1813-1823. 
Currie J. Healthy, wealthy, and wise: Socioeconomic status, poor health in childhood, and human capital development. Journal of Economic Literature. 2009; 47(1):87-122.

Cutler, DM.; Lleras-Muney, A. Education and Health: Evaluating theories and evidence. In: Schoeni, Robert F.; House, James S.; Kaplan, George; Pollack, Harold, editors. Making Americans Healthier: Social and Economics Policy as Health Policy. New York: Russell Sage Foundation; 2008.

Cutler DM, Lleras-Muney A. Understanding differences in health behaviors by education. Journal of Health Economics. 2010; 29(1):1-28. [PubMed: 19963292]

Cutler, DM.; Lleras-Muney, A.; Vogl, T. Socioeconomic Status and Health: Dimensions and Mechanisms. Glied, Sherry; Smith, Peter C., editors. Oxford Handbook of Health Economics; 2011.

Cutler DM, Lleras-Muney A. Education and Health: Insights from International Comparisons. NBER Working Paper 17738. 2012

Deaton AS, Paxson CH. Aging and inequality in income and health. American Economic Review. 1998; 88:248-253.

Deaton A. Policy implications of the gradient of health and wealth. Health Affairs. 2002; 21(2):13-30. [PubMed: 11900153]

Ehrlich I, Chuma H. A Model of the Demand for Longevity and the Value of Life Extension. Journal of Political Economy. 1990; 98(4):761-782. [PubMed: 11617449]

Ehrlich I, Lui FT. Intergenerational Trade, Longevity, and Economic Growth. Journal of Political Economy. 1991; 99(5):1029-1059.

Ehrlich I, Yin Y. Explaining Diversities in Age-Specific Life Expectancies and Values of Life Saving: A Numerical Analysis. Journal of Risk and Uncertainty. 2005; 31(2):129-162.

Erbsland, M.; Ried, W.; Ulrich, V. Health, health care, and the environment. Econometric evidence from German micro data. In: Jones, AM.; O’Donnell, O., editors. Health Economics. Econometric Analysis of Health Data. Vol. 4. New York: Wiley; 1995. 2002. p. 169-182.p. 25-36.Reprinted in.

Fonseca, R.; Michaud, P-C.; Kapteyn, A.; Galama, TJ. On the Rise of Health Spending and Longevity. Mimeo, University of Quebec au Montreal; 2013.

Forster M. The meaning of death: some simulations of a model of healthy and unhealthy consumption. Journal of Health Economics. 2001; 20(4):613-638. [PubMed: 11463191]

Fuchs; Viktor, R. The Health Economy. first ed.. Cambridge, MA: Harvard University Press; 1986.

Galama TJ, van Kippersluis H. A theory of socioeconomic disparities in health. RAND Working Paper. 2010 No. WR-773.

Galama TJ. A contribution to health capital theory. RAND Working Paper. 2011 No. WR-831.

Galama TJ, Kapteyn A, Fonseca R, Michaud PC. A Health Production Model with Endogenous Retirement. Health Economics. 2013 forthcoming.

Galama TJ, Hullegie P, Meijer E, Outcault S. Is there empirical evidence for decreasing returns to scale in a health capital model? Health Economics. 2012; 21(9):1080-1100. [PubMed: 22628203]

Garcia-Gomez P, van Kippersluis H, O’Donnell O, van Doorslaer E. Long term and spillover effects of health shocks on employment and income. Journal of Human Resources. 2013 forthcoming.

Gerdtham UG, Johannesson M. New estimates of the demand for health: results based on a categorical health measure and Swedish micro data. Social Science \& Medicine. 1999; 49:1325-1332. [PubMed: 10509823]

Gerdtham UG, Johannesson M, Lundberg L, Isacson D. The demand for health: results from new measures of health capital. European Journal of Political Economy. 1999; 15:501-521.

Gilleskie D. A Dynamic Stochastic Model of Medical Care Use and Work Absence. Econometrica. 1998; 66(1):1-45.

Gilleskie D. Work absences and doctor visits during an illness episode: The differential role of preferences, production, and policies among men and women. Journal of Econometrics. 2010; 156(1):148-163.

Glied S, Lleras-Muney A. Technological Innovation and Inequality in Health. Demography. 2008; 45(3):741-761. [PubMed: 18939670] 
Goldman DP, Smith JP. Can Patient Self-Management Help Explain the SES Health Gradient? Proceedings of the National Academy of Science. 2002; 99:10929-10934.

Grossman, M. The Demand for Health-A theoretical and Empirical Investigation. New York: National Bureau of Economic Research; 1972a.

Grossman M. On the Concept of Health Capital and the Demand for Health. The Journal of Political Economy. 1972b; 80(2):223-255.

Grossman, M. The Human Capital Model. In: Culyer, AJ.; Newhouse, JP., editors. Handbook of Health Economics. Vol. 1. Elsevier Science; 2000. p. 347-408.

Grossman, M. Education and Nonmarket Outcomes. In: Hanushek, Eric A.; Welch, Finis, editors. Handbook of the Economics of Education. Amsterdam: North-Holland; 2006.

Halla M, Zweimüller M. The Effect of Health on Income: Quasi-Experimental Evidence from Commuting Accidents. Labour Economics. 2013 forthcoming.

Healthy People 2020, Secretary's Advisory Committee on Health Promotion and Disease Prevention Objectives for 2020. Healthy People 2020: An Opportunity to Address the Societal Determinants of Health in the United States. 2010 Jul 26.

Heckman JJ. Skill Formation and the Economics of Investing in Disadvantaged Children. Science. 2006; 312(5782):1900-1902. [PubMed: 16809525]

Herd P. Do functional health inequalities decrease in old age? Research on Aging. 2006; 28(3):375392.

House JS, Lepkowski JM, Kinney AM, Mero RP, Kessler RC, Herzog AR. The social stratification of aging and health. Journal of Health and Social Behavior. 1994; 35:213-234. [PubMed: 7983335]

Hugonnier J, Pelgrin F, St-Amour P. Health and (Other) Asset Holdings. Review of Economic Studies. 2013; 80(2):663-710.

Jacobson L. The family as producer of health — an extension of the Grossman model. Journal of Health Economics. 2000; 19:611-637. [PubMed: 11184796]

Kaestner R. The Grossman model after 40 years: a reply to Peter Zweifel. European Journal of Health Economics. 2013 forthcoming.

Khwaja A. Estimating willingness to pay for medicare using a dynamic life-cycle model of demand for health insurance. Journal of Econometrics. 2010; 156(1):130-147.

Leu, RE.; Doppmann, RJ. Gesundheitszustandsmessung und Nachfrage nach Gesundheitsleistungen. In: Wille, E., editor. Informations- und Planungsprobleme in öffentlichen Aufgabenbereichen. Lang: Frankfurt am Main, Germany; 1986. p. 1-90.

Leu, RE.; Gerfin, M. Die Nachfrage nach Gesundheit: Ein empirischer Test des Grossman-Modells. In: Oberender, P., editor. Steuerungsprobleme im Gesundheitswesen. Nomos: Baden-Baden, Germany; 1992. p. 61-78.

Levine RS, Foster JE, Fullilove RE, Briggs NC, Hull PC, Husaini BA, Hennekens CH. Black-white inequalities in mortality and life expectancy, 1933-1999: Implications for Healthy People 2010. Public Health Reports. 2001; 116:474-483. [PubMed: 12042611]

Lleras-Muney A. The relationship between education and adult mortality in the United States. Review of Economic Studies. 2005; 72:189-221.

Lleras-Muney A, Lichtenberg F. The Effect of Education on Medical Technology Adoption: Are the More Educated More Likely to Use New Drugs. Annales d'Economie et Statistique. 2005 special issue in memory of Zvi Griliches, No 79/80.

Lynch SM. Cohort and Life-Course Patterns in the Relationship between Education and Health: A Hierarchical Approach. Demography. 2003; 40:309-331. [PubMed: 12846134]

Lynch JW, Kaplan GA, Shema SJ. Cumulative Impact of Sustained Economic Hardship on Physical, Cognitive, Psychological, and Social Functioning. New England Journal of Medicine. 1997; 337(26):1889-1895. [PubMed: 9407157]

Mackenbach JP, Kunst AE, Cavelaars AEJM, Groenhof F, Geurts JJM, et al. Socioeconomic inequalities in morbidity and mortality in western Europe. Lancet. 1997; 349:1655-1659. [PubMed: 9186383]

Marmot M, Ryff CD, Bumpass LL, Shipley M, Marks NF. Social inequalities in health: next questions and converging evidence. Social Science and Medicine. 1997; 44(6):901-910. [PubMed: 9080570] 
Marmot, M. Multi-level approaches to understanding social determinants. In: Berkman, Lisa; Icawachi, Ichiro, editors. Social Epidemiology. Oxford: Oxford University Press; 1999.

Meara ER, Richards S, Cutler D. The Gap Gets Bigger: Changes In Mortality And Life Expectancy, By Education, 1981-2000. Health Affairs. 2008; 27(2):350-360. [PubMed: 18332489]

Michaud P-C, van Soest A. Health and wealth of elderly couples: Causality tests using dynamic panel data models. Journal of Health Economics. 2008; 27(5):1312-1325. [PubMed: 18513809]

Mincer, JA. Schooling, Experience, and Earnings. Columbia: University Press; 1974.

Møller Dano A. Road Injuries and Long-Run Effects on Income and Employment. Health Economics. 2005; 14(9):955-970. [PubMed: 16127674]

Mushkin S. Health as an investment. Journal of Political Economy. 1962; 70(5):129-157.

Nocera, S.; Zweifel, P. The demand for health: an empirical test of the Grossman model using panel data. In: Zweifel, P., editor. Health, the Medical Profession, and Regulation. Boston, MA: Kluwer; 1998. p. 35-49.

Oreopoulos P. Estimating average and local average treatment effects of education when compulsory schooling laws really matter'. American Economic Review. 2006; 96(1):152-175.

Ravesteijn B, van Kippersluis H, van Doorslaer E. Research on Economic Inequality. Rosa Dias, Pedro; O'Donnell, OwenThe contribution of occupation to health inequality. John Bishop, Volume 21: Health and Inequality. 2013 Forthcoming.

Ried W. Comparative dynamic analysis of the full Grossman model. Journal of Health Economics. 1998; 17(4):383-425. [PubMed: 10180925]

Ross CE, Wu CL. Education, Age, and the Cumulative Advantage in Health. Journal of Health and Social Behavior. 1996; 37:104-120. [PubMed: 8820314]

Scholz JK, Seshadri A. The Interplay of Wealth, Retirement Decisions, Policy and Economic Shocks. Michigan Retirement Research Center Research Paper No. WP 2012-271. 2012

Schultz T. Investment in Human Capital. American Economic Review. 1961; 51:1-17.

Smith JP. Healthy bodies and thick wallets. Journal of Economic Perspectives. 1999; 13(2):145-166.

Smith, JP. Population and Development Review, Supplement: Aging, Health, and Public Policy-30. 2004. Unraveling the SES: Health Connection; p. 108-132.

Smith JP. The Impact of Socioeconomic Status on Health over the Life-Course. Journal of Human Resources. 2007; 42(4):739-764.

Usher, D. Comments on "The correlation between health and schooling”. In: Terleckyj, NE., editor. Household production and consumption. New York, NY: National Bureau of Economic Research; 1976. p. 212-220.(Available from: http://www.nber.org/chapters/c3962.pdf.)

Van de Ven WPMM, Van der Gaag J. Health as an unobservable: a MIMIC-model of demand for health care. Journal of Health Economics. 1982; 1:157-183. [PubMed: 10263954]

Van Doorslaer, EKA. Health, Knowledge and the Demand for Medical Care: An Econometric Analysis. Assen, Netherlands: Van Gorcum; 1987.

Van Kippersluis H, O'Donnell O, van Doorslaer E, Van Ourti T. Socioeconomic Differences in Health over the Life Cycle in an Egalitarian Country. Social Science and Medicine. 2010; 70(3):428-438. [PubMed: 19897296]

Van Kippersluis H, O'Donnell O, van Doorslaer E. Long Run Returns to Education: Does Schooling Lead to an Extended Old Age? Journal of Human Resources. 2011; 46(4):695-721.

Van Kippersluis H, Galama TJ. Why the Rich Drink More but Smoke Less: The Impact of Wealth on Health Behaviors. RAND Working Paper, WR-988. 2013

Wagstaff A. The demand for health: some new empirical evidence. Journal of Health Economics. 1986; 5:195-233. [PubMed: 10279033]

Wagstaff A. The demand for health: an empirical reformulation of the Grossman model. Health Economics. 1993; 2:189-198. [PubMed: 8261039]

Williams DR, Jackson PB. Social sources of racial disparities in health. Health Affairs. 2005; 24(2): 325-334. [PubMed: 15757915]

World Health Organization. Report of the Commission on Macroeconomics and Health. Geneva: 2001. Macroeconomics and health: Investing in health for economic development. 2001. 
World Health Organization. Final Report of the Commission on Social Determinants of Health. Geneva: World Health Organization; 2008. Closing the Gap in a Generation: Health Equity through Action on the Social Determinants of Health.

Yogo M. Portfolio Choice in Retirement: Health Risk and the Demand for Annuities, Housing, and Risky Assets. PARC Working Papers Population Aging Research Center. 2009

Zweifel, P.; Breyer, F. Health Economics. New York, NY: Oxford University Press; 1997.

Zweifel P. The Grossman model after 40 years. European Journal of Health Economics. 2012; 13(6): 677-682. [PubMed: 22955523] 

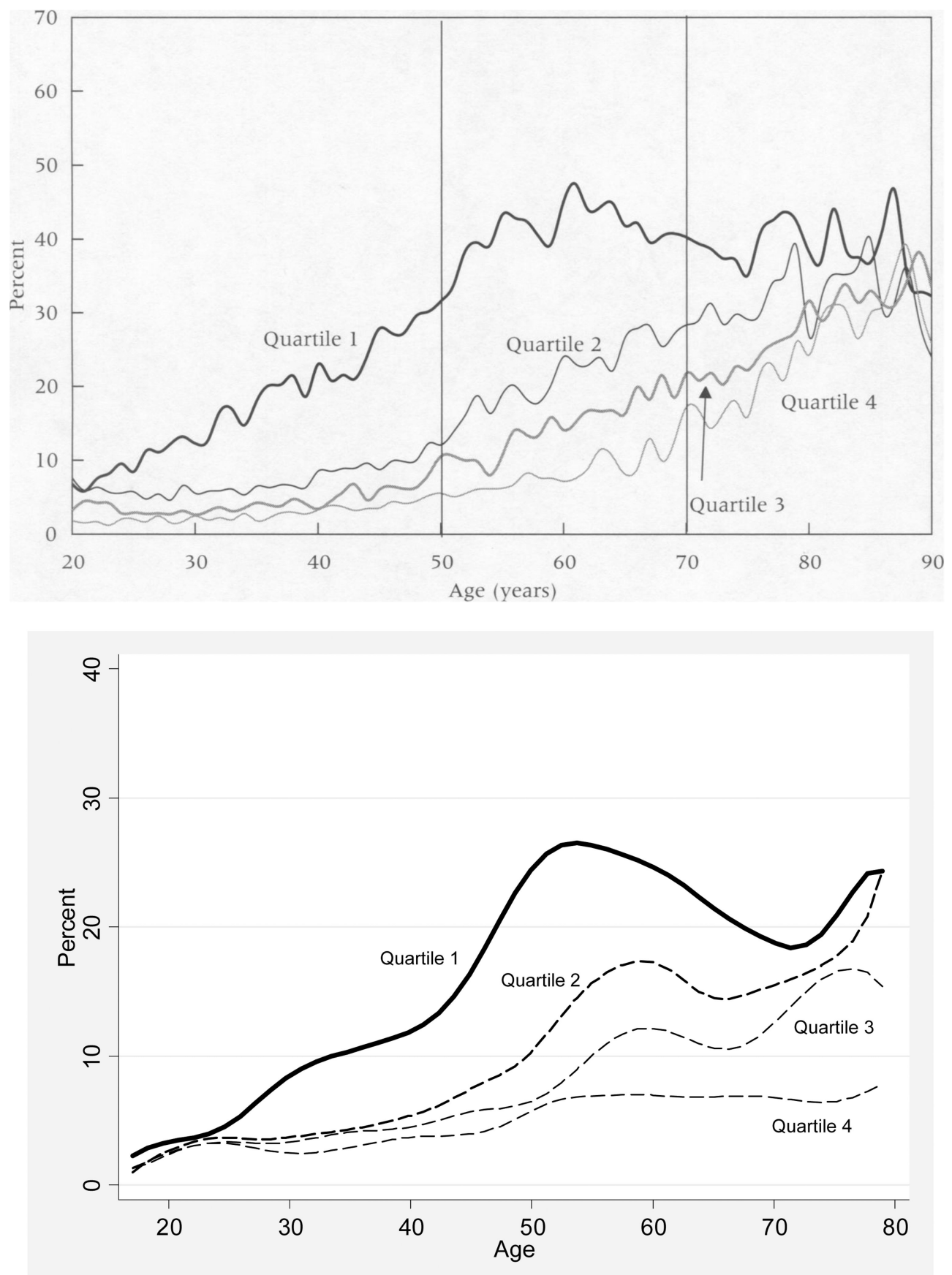

Fig. 1.

Percentage reporting fair or poor health (bottom two categories of self-reported health) by age-specific household income quartiles. Top: US National Health Interview Surveys, 19911996, taken from Smith (2004) ${ }^{7}$. Bottom: Dutch CBS Health Interview Surveys, 1983-2000, own calculations

${ }^{7}$ This material is reproduced with permission of John Wiley \& Sons, Inc. Smith, J.P. (2004). "Unraveling the SES: Health Connection”, Population and Development Review, Supplement: Aging, Health, and Public Policy, 30: 108-132. 